Seção Temática: Balanço do Fundeb Volume 10 - $2020 \mid$ n. 28

\title{
Educação especial e o Fundeb: histórico, balanço e desafios
}

\author{
Marcia Maurilio Souza \\ Universidade de São Paulo (USP), São Paulo/SP - Brasil \\ Marileide Gonçalves França \\ Universidade Federal do Espírito Santo (UFES), Vitória/ES - Brasil \\ Vanessa Dias Bueno de Castro \\ Rosângela Gavioli Prieto \\ Universidade de São Paulo (USP), São Paulo/SP - Brasil
}

\section{Resumo}

A educação especial brasileira, como modalidade de ensino, tem orientação inclusiva, contudo, assegurar a permanência e acesso ao conhecimento requer investimento financeiro. Considerando esse cenário, objetiva-se analisar os recursos da educação especial no contexto do Fundeb em nível nacional e nas redes estaduais de ensino paulista e capixaba, de 2009 a 2019. As fontes documentais analisadas foram as matrículas da educação especial, os valores aluno/ano e as despesas com educação e educação especial. Dos resultados depreende-se que o montante destinado a essa modalidade foi ampliado, o que pode ter repercutido no aumento de matrículas nessas redes. As despesas da subfunção educação especial também indicaram uma trajetória crescente, embora não tenha sido possível analisar os valores específicos do Fundeb com essa modalidade de ensino. Desse modo, o estudo aponta a necessidade de alteração nos demonstrativos de despesas, a fim de garantir o acompanhamento e o controle dos recursos vinculados à educação especial.

Palavras-chave: Financiamento da educação. Educação Especial. Fundeb.

\section{Special education and Fundeb: history, balance and challenges}

\begin{abstract}
Brazilian special education, as a teaching modality, has an inclusive orientation, however, ensuring the permanence and access to knowledge requires financial investment. Considering this scenario, it aims to analyze the resources of special education in the context of Fundeb at the national level and in the state education networks of São Paulo and Espírito Santo, from 2009 to 2019. The documentary sources analyzed were enrollments for special education, student/year values, and expenses for education and special education. From the results, it appears that the amount allocated to this modality was increased, which may have had an impact on the increase in enrollment in these networks. Expenses from the special education subfunction also indicated an increasing trajectory, although it was not possible to analyze the specific values of Fundeb with this modality of teaching. Thereby, the study points out the need to change the statements of expenses, in order to guarantee the monitoring and control of resources linked to special education.
\end{abstract}

Keywords: Education Funding. Special education. Fundeb. 
Educação especial e o Fundeb

\section{Introdução}

A Constituição da República Federativa do Brasil de 1988 (CF/1988) conclama o direito à educação na esfera dos direitos sociais, como dever do Estado e da família, além de dever ser promovida e incentivada em colaboração com a sociedade (BRASIL, 1988).

A Carta Magna também assevera a necessidade de haver equidade na oferta da educação, a partir da criação de condições que garantam acesso, permanência e aprendizagem a todos(as). Portanto, é compromisso do Estado brasileiro atingir os mais vulneráveis por meio de políticas que diminuam a desigualdade social e educacional. Nesse contexto, as pessoas com deficiência, transtornos globais do desenvolvimento (TGD) e altas habilidades/superdotação têm seu direito à educação assegurado na CF/1988 e ratificada na Lei de Diretrizes e Bases da Educação Nacional - LDB/1996 (BRASIL, 1996a) e em normas posteriores. Embora nessas leis maiores esteja firmado que a educação escolar deva ser preferencialmente na rede regular de ensino, o incentivo à adoção da orientação inclusiva, com mais vigor após os anos 2000 , resultou em ampliação do acesso via classe comum em detrimento de formas de atendimento em espaços segregados.

Em 2019, segundo dados sistematizados pelo Instituto Nacional de Estudos e Pesquisas Educacionais Anísio Teixeira (Inep) nas Sinopses Estatísticas da Educação Básica, o total de matrículas da educação especial ${ }^{1}$ atingiu 1.250 .967 , aumento de $95,5 \%$ em relação ao ano de 2009, quando esse total foi de 639.718. De modo específico, esse acréscimo decorreu do aumento de $181,8 \%$ das matrículas em classes comuns nesse período (de 387.031 para 1.090.805), haja vista que as matrículas em escolas e classes especiais sofreram redução de $36,6 \%$ (de 252.687 para 160.162). Em relação ao total de matrículas na educação básica, as da educação especial correspondiam a 1,2\% em 2009 e passaram a representar $2,4 \%$ em 2019.

Para que o direito à educação dessa população seja consolidado faz-se necessário o financiamento público, em regime de cooperação federativa entre União, estados e municípios. Na LDB/1996, em seu art. $4^{\circ}$, inc. IX foi estabelecido o dever do Estado com a educação, mediante a garantia de "[...] padrões mínimos de qualidade de ensino, definidos como a variedade e quantidade mínimas, por aluno, de insumos indispensáveis ao desenvolvimento do processo de ensino-aprendizagem" (BRASIL, 1996a). No Brasil, o padrão de qualidade está relacionado aos recursos mínimos disponibilizados pela vinculação constitucional e ao valor aluno/ano definido pela política de fundos (OLIVEIRA, 2007). Logo, - Estado deve garantir a aplicação mínima de recursos em educação para a manutenção e desenvolvimento do ensino, com vistas a atingir um padrão mínimo de qualidade.

Essa garantia de recursos públicos para financiar a educação tem se configurado por meio das políticas de fundos, de modo mais incisivo a partir de 1996, com a implementação do Fundo de Manutenção e Desenvolvimento do Ensino Fundamental e de Valorização do Magistério (Fundef)2 ${ }^{2}$ que teve vigência até 2006, sendo substituído pelo Fundo de

1 As matrículas totais englobam as registradas em classes comuns, classes especiais e escolas exclusivamente especializadas.

2 Instituído pela Lei Federal n 9.424, o Fundef: "Dispõe sobre o Fundo de Manutenção e Desenvolvimento do Ensino Fundamental e de Valorização do Magistério, na forma prevista no art. $60, \S 7^{\circ}$, do Ato das Disposições Constitucionais Transitórias, e dá outras providências" (BRASIL, 1996b). 
Manutenção e Desenvolvimento da Educação Básica e de Valorização dos Profissionais da Educação (Fundeb) no ano de 2007, o qual trouxe alterações no padrão de financiamento da educação básica, a partir de mecanismos de distribuição de recursos para todas as etapas e modalidades de ensino. Considerando essa realidade, a questão que norteou este estudo foi: como se caracterizou o financiamento da educação especial no contexto do Fundeb no Brasil e nas redes estaduais de ensino de São Paulo e Espírito Santo?

Constata-se, nesse período de vigência dos fundos, uma expansão na produção de pesquisas sobre financiamento da educação, porém, em relação ao financiamento da educação especial o acúmulo ainda é tímido. Levantamento realizado, sobre pesquisas voltadas à análise dos efeitos do Fundeb para essa modalidade de ensino ${ }^{3}$, apontam como aspectos positivos o fato de contemplar toda a educação básica, ter contribuído para a ampliação das matrículas do público elegível ao atendimento pela educação especial, assim como aumento dos recursos destinados a essa modalidade de ensino. Também destacam, em contraponto, o direcionamento dos recursos públicos para as instituições privadas.

Martins (2009) afirma que o Fundeb se constituiu em instrumento que melhorou a garantia da equanimidade da educação básica, apesar de ter criado alguns problemas como a inclusão das matrículas privadas da educação especial e das creches, dentre as financiáveis pelo Fundo. Em relação à equanimidade, Teixeira (2015) confirmou essa distribuição de recursos para a educação proporcionada pelo Fundeb, se comparado ao Fundef, no estado de Goiás entre 2010 e 2013.

Embora ocorra o repasse de verbas do Fundeb para matrículas vinculadas às unidades educacionais privadas, como aponta Martins (2009), Bassi (2012), ao analisar as matrículas da educação especial no estado de Santa Catarina, no período de 1996-2011, em que vigoraram o Fundef e o Fundeb, identificou a ampliação de matrículas de alunos(as) da educação especial na esfera pública induzidos pela política de financiamento de fundos. Fato também constatado por Pereira (2012) em sua pesquisa envolvendo dados de João Pessoa e Cabedelo, ambos municípios do estado da Paraíba/PB, abrangendo o intervalo entre 20052010. Teixeira (2015) destaca que as matrículas se concentravam nas séries iniciais do ensino fundamental, de maior responsabilidade da administração municipal. Pereira (2012) e Teixeira (2015) ainda concluem que houve o aumento de matrículas no atendimento educacional especializado (AEE).

Bassi (2012) também relata que, em 2009, o estado de Santa Catarina perdeu financiamento por uma mudança na contabilização no censo escolar das matrículas nas instituições especializadas, mas que a migração das matrículas para a esfera pública e a dupla matrícula do(a) aluno(a) da educação especial (na classe comum e no atendimento educacional especializado) ajudaram a manter o patamar de financiamento da educação especial no estado. Pereira (2012), por sua vez, observou que em João Pessoa/PB os recursos gastos com a educação especial eram originários das fontes orçamentárias do Fundeb, de convênios federais e do salário-educação, ao passo que, em Cabedelo/PB, esses gastos não foram discriminados, ou seja, foram agregados aos gastos do ensino fundamental.

3 As buscas foram realizadas nos portais do SciELO, Biblioteca Brasileira de Teses e Dissertações, Capesperiódicos e Revista Fineduca. Usou-se para as buscas as palavras-chave: Educação Especial e Fundeb. 
A autora indica que os dois municípios priorizaram o uso dos recursos associados às matrículas dos(as) alunos(as) com vínculo na educação especial no ensino fundamental.

Em relação às verbas da educação especial, França (2014) constatou que, no município de Vitória, capital do estado do Espírito Santo/ES, entre 2008-2010 ocorreu o mesmo, além de esses valores serem subdimensionados e parecerem não corresponder às despesas reais. Nesse sentido, afirma que os mecanismos de prestação de contas públicas das verbas da educação especial no Fundeb não contribuíram para garantir a transparência, organização e padronização dos dados financeiros das etapas e modalidades de ensino, com destaque para a educação especial.

A partir dessas considerações, esta pesquisa tem como objetivo analisar os recursos da educação especial no contexto Fundeb em nível nacional e nas redes de ensino estaduais de São Paulo e do Espírito Santo, entre 2009 e 2019, em função de 2009 ter sido o término da implantação do Fundeb e, 2019, por ser o último ano de dados consolidados das despesas educacionais dos referidos estados. Justifica-se a escolha dos estados por ambos terem um histórico de atendimento ao público elegível pela educação especial, portanto, apresentam matrículas e serviços voltados à permanência e aprendizagem no contexto dos sistemas de ensino comum, além de as pesquisadoras residirem e desenvolverem pesquisas nesses estados.

O estado de São Paulo, de acordo com o Instituto Brasileiro de Geografia e Estatística (IBGE), possui área territorial de $248.219,481 \mathrm{Km}^{2}$ e população estimada em $45.919 .049 \mathrm{em}$ 2019. Seu Índice de Desenvolvimento Humano ${ }^{4}$ (IDH) é de 0,783 (dados de 2010) - o segundo maior do país - e o rendimento domiciliar mensal per capita foi de $\mathrm{R} \$ 1.946,00$ no ano de 2019. Em relação às finanças públicas, os dados de $2017^{5}$ indicam que o total de receitas orçamentárias foi de $\mathrm{R} \$ 232.822 .496 .567,06$.

Pela mesma fonte, o estado do Espírito Santo possui área territorial de $46.074,447 \mathrm{Km}^{2}$ e no ano de 2019 a população foi estimada em 4.018.650 habitantes. Dados de 2010 indicam que o IDH é de 0,740 - o $8^{\circ}$ no país, em comparação aos outros estados - e o rendimento domiciliar mensal per capita foi de $\mathrm{R} \$ 1.477,00$ no ano de 2019. Em 2017 o total de receitas orçamentárias foi de $\mathrm{R} \$ 1$ 19.685.616.743.76.

Cumpre destacar que esses estados têm grande potencial de arrecadação tributária, que repercute nos valores aluno/ano acima da média nacional, portanto, maior quantitativo de verbas destinadas à educação, exemplo disso está no valor aluno/ano nacional para matrículas nos anos iniciais do ensino fundamental urbano em 2019 , que foi de $R \$ 3.479,85$, ao passo que para São Paulo foi de $R \$ 4.132,57$ e, para o Espírito Santo, de $R \$ 3.821,95$. Ademais, são estados que se destacam na região Sudeste no que tange ao desenvolvimento de pesquisas voltadas ao financiamento da educação especial ${ }^{6}$. Desse modo, o estudo nas

4 "O IDH mede o progresso de uma nação a partir de três dimensões: renda, saúde e educação". Disponível em: https://bit.ly/3e74q2D. Acesso em: 22 maio 2020.

5 Os dados de 2017 eram os mais atuais disponíveis no endereço eletrônico do IBGE no momento da consulta realizada.

6 Algumas das pesquisas desenvolvidas nos estados: Soto et al. (2012), Loureiro (2013), França (2014), Oliveira (2016), Silva (2016), França e Prieto (2018), Oliveira e Sobrinho (2020), Souza, Castro e Prieto (2020), Souza e Prieto (2020). 
suas respectivas redes de ensino pode apontar novas possibilidades sobre as políticas de financiamento dessa modalidade de ensino no Brasil.

Trata-se de uma pesquisa documental (LUDKE; ANDRÉ, 1986; GIL, 1991), com fontes primárias, pois vale-se de materiais que não receberam ainda um tratamento analítico e que podem auxiliar a compreensão sobre o quantitativo de recursos e o destino das despesas vinculadas à educação especial no âmbito do Fundeb.

Para tanto, foram consultados os dados dos censos escolares realizados pelo Inep, os valores aluno/ano do Fundeb, extraídos do portal do Fundo Nacional de Desenvolvimento da Educação (FNDE). Os dados referentes às despesas liquidadas ${ }^{7}$ do Fundeb, da função ${ }^{8}$ educação e da subfunção ${ }^{9}$ educação especial foram consultados no Sistema de Informações sobre Orçamentos Públicos em Educação (Siope) ${ }^{10}$.

As informações foram organizadas em gráficos e tabelas para auxiliar as análises e compreensão dos valores aluno/ano previstos para a educação especial, articulados ao número de matrículas e às despesas vinculadas a essa modalidade de ensino, nas redes de ensino estaduais do Espírito Santo e São Paulo.

Este artigo é apresentado em duas seções, além desta introdução e das considerações finais. A primeira discorre sobre a caracterização da educação especial no contexto do Fundeb. A segunda apresenta as análises das matrículas e dos recursos dessa modalidade de ensino no Brasil e nas respectivas redes estaduais de ensino.

\section{A educação especial no contexto do Fundeb}

O Fundeb foi criado pela Emenda Constitucional $n^{\circ} 53$, regulamentado pela Lei $n^{\circ}$ 11.494 e pelo Decreto $n^{\circ} 6.253$, em substituição ao Fundef. Sua vigência foi estabelecida no período de 2007 a 2020 (BRASIL, 2006; 2007a; 2007b). Constitui-se como um fundo especial, de natureza contábil, no âmbito estadual, e sua formação resulta da aplicação de percentuais, vinculados à receita proveniente da arrecadação de impostos ${ }^{11}$ do Distrito Federal, dos estados e municípios, direcionados à educação por força do disposto no art. 212 da CF/1988 (BRASIL, 1988). Ainda compõe o Fundeb, a título de complementação, uma parcela de recursos da União, sempre que, no âmbito de cada estado, o valor por aluno não alcançar o mínimo definido nacionalmente, em cada uma das etapas ou modalidades de ensino, fixado

7 O valor liquidado se refere à verificação do direito adquirido pelo credor de receber o pagamento (BRASIL, 1964). É o segundo estágio da execução de despesa, precedido do empenho e antecedido do pagamento.

8 De acordo com Polo (1999), a despesa por função corresponde ao maior nível de agregação das diversas áreas de despesas que competem ao setor público, com a finalidade de especificar em que campo a ação governamental será realizada (como exemplo, educação, saúde, trabalho, cultura, entre outras funções).

9 A subfunção "[...] representa um nível de agregação imediatamente inferior à função e deve evidenciar cada área de atuação governamental” (SÃO PAULO, 2018, p. 19).

10 A consulta foi realizada nos relatórios estaduais, por meio do Relatório Resumido da Execução Orçamentária - Demonstrativo das Receitas e Despesas com o Fundo de Manutenção e Desenvolvimento da Educação Básica e de Valorização dos Profissionais.

11 No Fundeb estão incluídos os impostos que já faziam parte do Fundef: Imposto sobre Circulação de Mercadorias e Serviços (ICMS), Fundo de Participação dos Municípios (FPM), Fundo de Participação dos Estados (FPE), Imposto sobre Produtos Industrializados, proporcional às exportações (IPI-exp) e ressarcimento pela desoneração de Exportações de que trata a LC n 87/96 (aumentados de 15\% para 20\%), acrescidos do Imposto sobre Propriedade de Veículos Automotores (IPVA), Imposto Territorial Rural (ITR) e Imposto sobre Transmissão Causa Mortis e Doações (ITCMD). Também compõem o Fundo as receitas da dívida ativa e de juros e multas incidentes sobre as fontes relacionadas. 
pelo Poder Executivo, de acordo com o inc. V, do art. $2^{\circ}$ da Emenda Constitucional $n^{\circ} 53$ (BRASIL, 2006).

O Fundeb garante que a maior parte dos recursos vinculados à educação seja aplicada à educação básica, por meio de seu mecanismo de distribuição de recursos com base no número de matrículas das diversas etapas e modalidades informado no censo escolar do ano anterior.

A distribuição de recursos também considera os fatores de ponderação que são definidos anualmente pela Comissão Intergovernamental de Financiamento para a Educação Básica de Qualidade, conforme previsto no inc. I do art. 13 da Lei nº 11.494 (BRASIL, 2007a). As etapas e modalidades são consideradas com pesos diferenciados na distribuição de recursos, situados em uma escala entre 0,8 a 1,3 pontos $^{12}$, tendo como referência o fator de ponderação 1,0 , definido para a matrícula dos anos iniciais urbanos do ensino fundamental (BRASIL, 2018). O valor mínimo por aluno/ano da educação especial passa a receber um peso ponderado $20 \%$ superior ao valor/aluno ano de referência, não tendo sofrido alterações no período de 2007 a 2019.

No intuito de garantir a implementação da Política Nacional da Educação Especial na Perspectiva da Educação Inclusiva (BRASIL, 2008), que tinha como objetivo assegurar a inclusão escolar dos(as) alunos(as) com deficiência, TGD e altas habilidades/superdotação, foi aprovado o Decreto $n^{0} 7.611$ (BRASIL, 2011a) com a finalidade de garantir o compromisso da União na prestação de apoio técnico e financeiro aos sistemas públicos de ensino do Distrito Federal, dos estados e municípios, para o AEE. A partir desse Decreto, esses(as) alunos(as) passaram a ser contabilizados duplamente no âmbito do Fundeb, quando matriculados em classes comuns do ensino regular e no AEE, podendo este ser realizado na mesma escola que o aluno frequenta, em outra do seu entorno ou por instituições comunitárias, confessionais ou filantrópicas, sem fins lucrativos, com atuação exclusiva em educação especial.

Cumpre destacar que o financiamento da educação especial foi apontado como uma das estratégias para garantir a universalização do acesso dos(as) alunos(as) elegíveis ao atendimento pela educação especial na educação básica na meta 4 do Plano Nacional de Educação, Lei n. ${ }^{\circ} 13.005$ (BRASIL, 2014). Contudo, no processo de sua tramitação, foram assegurados recursos públicos às instituições privadas de ensino para a oferta do AEE e educação especial substitutiva. Um importante instrumento no sentido de romper com a lógica que pauta o financiamento da educação no Brasil tem sido a definição dos referenciais do Custo Aluno-Qualidade Inicial (CAQi), elaborado pela Campanha Nacional pelo Direito à Educação no documento Educação pública de qualidade (BRASIL, 2011b), ratificado pelo Plano Nacional de Educação (2014-2024), na Meta 20 (BRASIL, 2014b), com o objetivo de definir um custo por aluno capaz de garantir um padrão mínimo de qualidade, como previsto na CF/1988 e na LDB/1996.

Com base no exposto e diante do término da vigência do Fundeb, faz-se necessário refletir acerca dos valores destinados à educação especial, se essa política tem contribuído

12 O menor fator de ponderação 0,8 se refere à creche conveniada em tempo parcial e Educação de Jovens e Adultos e, o maior, de 1,3, corresponde à creche pública em tempo integral, pré-escola integral, ensino fundamental integral, ensino médio urbano, ensino médio no campo e ensino médio integrado à educação profissional (BRASIL, 2018). 
para a ampliação de recursos e se é possível visualizá-los nas despesas voltadas a essa modalidade de ensino nos estados de São Paulo e Espírito Santo.

\section{Valor aluno/ano da educação especial do Fundeb no Brasil e nos estados do Espírito Santo e São Paulo}

Os valores aluno/ano definidos pelo Fundeb para matrículas dos anos iniciais do ensino fundamental urbano, utilizados como padrão de referência, da educação especial no Brasil e nos estados do Espírito Santo e São Paulo, no período de 2009 a 2019, são apresentados no Gráfico 1.

Gráfico 1 - Valor aluno/ano definido pelo Fundeb da educação especial no Brasil, Espírito Santo e São Paulo - 2009 a 2019 (R\$)

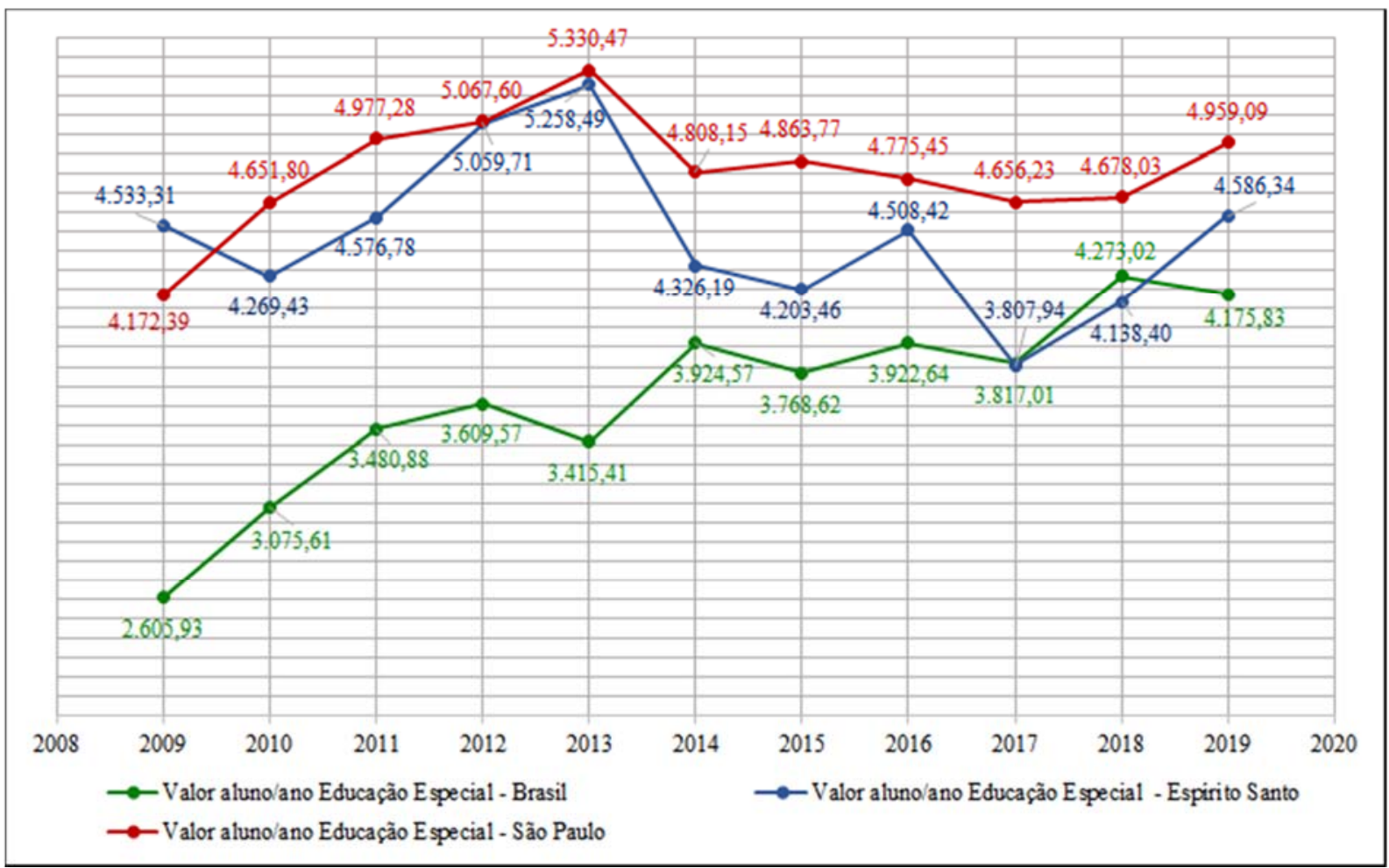

Nota: Valores atualizados com base no IPCA/IBGE de 12/2019.

Fonte: Elaboração das autoras com base em MEC/FNDE (BRASIL, 2009-2019).

A trajetória dos valores aluno/ano da educação especial no Brasil revela oscilação no período de 2009 a 2019, com aumento de $39 \%$ de 2009 a 2012, decréscimos nos anos de 2013 (5\%), 2015 (4\%), 2017 (3\%) e 2019 (2\%) e crescimento nos anos de 2014 (15\%), 2016 (4\%) e 2018 (12\%), em relação ao ano anterior. A redução nos valores no Fundeb, a partir de 2014, pode ser compreendida pelo cenário de retração econômica sobre a arrecadação de impostos, apontada por Pinto (2017), que atinge os recursos que financiam a educação básica. Assim, para os valores aluno/ano da educação especial de 2009 e 2019, é possível identificar um aumento de aproximadamente $60 \%$.

Os valores aluno/ano da educação especial do Espírito Santo e de São Paulo também apresentaram variações no período de 2009 a 2019, com decréscimos nos anos de 2010 (ES/6\%), 2014 (ES/18\% e SP/10\%), 2015 (ES/3\%), 2016 (SP/2\%) e 2017 (ES/16\% e SP/4\%). A queda nos valores no Fundeb a partir de 2014 se articula com a crise financeira no Brasil, 
destacada por Pinto (2017). Cabe ressaltar que, nos anos de 2015 em São Paulo e em 2016 no Espírito Santo, evidencia-se um pequeno aumento no valor aluno/ano $(1 \%$ e $7 \%$, respectivamente), porém, nos anos seguintes os valores sofrem reduções. Em 2018 é possível verificar um aumento de 9\% no Espírito Santo e 0,5\% em São Paulo. Esse movimento se repete em 2019, 11\% e 6\%, nessa ordem. Desse modo, os valores aluno/ano da educação especial de 2019 (R \$ 4.586,34/ES e R \$ 4.959,09/SP) são superiores aos valores de 2014 (R\$ $4.326,19 / E S$ e $R \$ 4.808,15 / S P)$, antes da crise, e 2009 (R $\$ 4.533,31 / E S$ e $R \$ 4.172,39 / S P)$, ano de consolidação do Fundeb, quando estava incluído o total das matrículas da educação básica pública presencial e os percentuais de receitas que o compunham alcançavam o patamar de $20 \%$. Portanto, o valor aluno/ano da educação especial nos estados do Espírito Santo e São Paulo, no período de 2009 a 2019, revela um crescimento de 1\% e 19\%, respectivamente.

Assim, verifica-se que o movimento nos valores aluno/ano da educação especial no Brasil e nos dois estados aponta para uma trajetória crescente, apesar das oscilações, no período em tela, repercutindo o aumento das receitas, no âmbito do Fundeb, destinadas a essa modalidade de ensino nesses dois estados e no Brasil. Nessa perspectiva, o efeito indutor do aumento de matrículas da política do Fundeb pode ser observado "[...] tanto no desempenho ascendente dos valores por aluno/ano, quanto no destacado aumento da diferença desse valor aluno da educação especial em relação ao das séries iniciais urbanas do ensino fundamental" (BASSI, 2012, p. 11).

A análise revela também a diferença do valor aluno/ano da educação especial dos estados em comparação ao do Brasil. Os valores do estado do Espírito Santo (exceto nos anos de 2017 e 2018) e de São Paulo estão acima do valor/aluno nacional, durante o período de 2009 a 2019, sendo que, em 2019, o valor aluno/ano da educação especial para São Paulo foi $18,75 \%$ e, para o Espírito Santo, foi $9,83 \%$ superiores ao nacional. Os fatores que têm se constituído como determinantes para o aumento do volume de recursos a ser investido em educação são o cômputo progressivo das matrículas e a capacidade de arrecadação de impostos dos estados (ANUNCIAÇÃO; VERHINE, 2006). Esses aspectos também ajudam a compreender a diferença do valor aluno/ano da educação especial no estado de São Paulo e Espírito Santo, ao longo dessa década.

Diante desse cenário, cabe analisar se o movimento ascendente dos valores aluno/ano da educação especial no Brasil e nos referidos estados repercutiu na trajetória de matrículas dessa modalidade de ensino.

\section{Matrículas da educação especial no Brasil, São Paulo e Espírito Santo}

De acordo com dados obtidos por meio das Sinopses Estatísticas da Educação Básica realizado anualmente pelo Inep, no período entre 2009 e 2019, os indicadores de matrícula em nível nacional indicam que houve aumento em todos os anos na modalidade educação especial nas dependências administrativas estaduais, passando de 132.920 para 354.840 , o que corresponde a $167 \%$-, como pode ser observado no Gráfico 2. 
Educação especial e o Fundeb

Gráfico 2 - Número de matrículas do alunado elegível ao atendimento pela educação especial nas redes estaduais entre 2009 e 2019 - Brasil, São Paulo e Espírito Santo

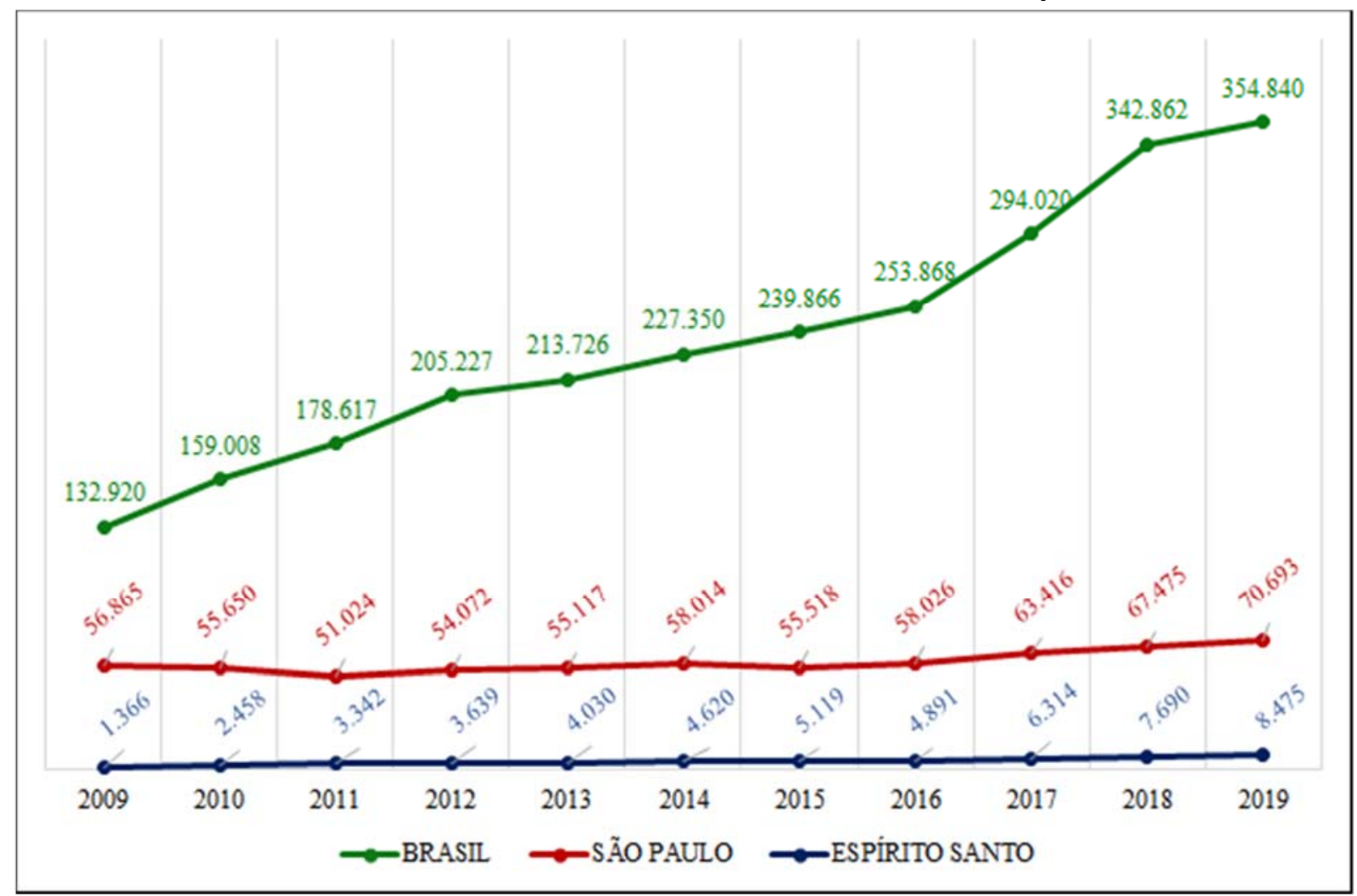

Fonte: Elaboração das autoras com base nas Sinopses Estatísticas do Censo Escolar, Inep (BRASIL, 2010 a 2020).

Tendo como parâmetro de comparação o ano anterior, observa-se que ocorreram consecutivos aumentos no número de matrículas no período analisado em âmbito nacional: 2010 (19,6\%), 2011 (12,3\%), 2012 (14,9\%), 2013 (4,1\%), 2014 (6,4\%), 2015 (5,5\%), 2016 (5,8\%), 2017 (15,8\%), 2018 (16,6\%) e 2019 (3,5\%). Não foram encontradas na literatura justificativas para tais aumentos, sendo necessária a realização de outros estudos a fim de compreender esse movimento.

$\mathrm{Na}$ rede estadual de ensino de São Paulo, embora tenha ocorrido aumento de matrículas na ordem de $24,3 \%$ no ano de 2019 , em comparação a 2009 , ocorreram oscilações nesse intervalo. Em comparação ao ano anterior, foram registradas reduções de 2,1\% e 8,3\% em 2010 e 2011, respectivamente, seguido por aumentos: 2012 (6,0\%), 2013 (1,9\%) e 2014 $(5,3 \%)$. Novo decréscimo ocorreu em 2015 (4,3\%). Nos anos subsequentes, ocorreram acréscimos em 2016 (4,5\%), 2017 (9,3\%), 2018 (6,4\%) e 2019 (4,8\%), sem nunca ter atingido a casa dos $10 \%$. Cabe observar que fica a indicação de tema para outro estudo, que foge ao escopo deste, que poderia analisar a correlação do movimento expressivo de matrículas na rede municipal de ensino da cidade de São Paulo e sua contribuição para essa tímida expansão de matrículas na rede estadual.

A rede estadual de ensino do Espírito Santo registrou aumento expressivo no período analisado - 520,5\%. De 2010 a 2015 ocorreram consecutivos aumentos percentuais no número de matrículas em relação ao ano anterior: 2010 (79,9\%), 2011 (36,0\%), 2012 (8,9\%), $2013(10,7 \%), 2014$ (14,6\%) e 2015 (10,8\%). No ano de 2016 foi registrada a única redução no número de matrículas: 4,5\%. Nos anos seguintes, os acréscimos foram: 2017 (29,1\%), 
$2018(21,8 \%)$ e $2019(10,2 \%)$. Frente a esse incremento de matrículas percentualmente expressivo, cabe indagar se ele seria decorrente de um efetivo aumento das matrículas, de um movimento para melhor identificação desse alunado ou de identificações equivocadas baseadas apenas em comportamentos dos alunos ou de não aprendizagem ${ }^{13}$. Ademais, estudos sobre os movimentos de matrículas nas dependências administrativas municipais podem trazer elementos importantes a essa análise, tal como já apontado.

Esses aumentos em números absolutos, apresentados no Gráfico 2, refletiram diretamente no percentual das matrículas do alunado elegível ao atendimento pela educação especial em relação ao total de matrículas da educação básica da dependência administrativa estadual, como pode ser verificado na Tabela 1.

Tabela 1 - Percentual de matrículas do alunado elegível ao atendimento pela educação especial em relação ao total de matrículas nas redes estaduais entre 2009 e 2019 - Brasil, São Paulo e Espírito Santo

\begin{tabular}{rrrr}
\hline & BRASIL & \multicolumn{1}{l}{ SP } & \multicolumn{1}{l}{ ES } \\
\hline $\mathbf{2 0 0 9}$ & $0,6 \%$ & $1,2 \%$ & $0,5 \%$ \\
$\mathbf{2 0 1 0}$ & $0,8 \%$ & $1,2 \%$ & $0,8 \%$ \\
$\mathbf{2 0 1 1}$ & $0,9 \%$ & $1,1 \%$ & $1,1 \%$ \\
$\mathbf{2 0 1 2}$ & $1,1 \%$ & $1,2 \%$ & $1,2 \%$ \\
$\mathbf{2 0 1 3}$ & $1,2 \%$ & $1,3 \%$ & $1,4 \%$ \\
$\mathbf{2 0 1 4}$ & $1,3 \%$ & $1,4 \%$ & $1,6 \%$ \\
$\mathbf{2 0 1 5}$ & $1,5 \%$ & $1,4 \%$ & $1,9 \%$ \\
$\mathbf{2 0 1 6}$ & $1,5 \%$ & $1,4 \%$ & $1,8 \%$ \\
$\mathbf{2 0 1 7}$ & $1,8 \%$ & $1,6 \%$ & $2,4 \%$ \\
$\mathbf{2 0 1 8}$ & $2,2 \%$ & $1,8 \%$ & $3,1 \%$ \\
$\mathbf{2 0 1 9}$ & $2,3 \%$ & $1,9 \%$ & $3,4 \%$ \\
\hline
\end{tabular}

Fonte: Elaboração das autoras com base nas Sinopses Estatísticas do Censo Escolar, Inep (BRASIL, 2010 a 2020).

No âmbito nacional, houve um aumento constante nas matrículas do alunado elegível ao atendimento pela educação especial nas redes estaduais, passando de $0,6 \%$ do total de matrículas da educação básica em 2009 para 2,3\% em 2019. As matrículas registradas na rede estadual de ensino do estado de São Paulo, embora tenham registrado um pequeno decréscimo em 2011, também aumentaram em relação ao total da educação básica, passando de 1,2\% em 2009 e chegando a representar 1,9\% do total em 2019. As matrículas da rede estadual de ensino do estado do Espírito Santo, por sua vez, registraram aumentos consecutivos em todos os anos do período analisado, passando de 0,5\% em 2009 para 3,4\% em 2019, ou seja, houve um aumento percentual mais expressivo.

13 Para responder a essa questão, seria necessário recorrer aos microdados do Censo Escolar a fim de analisar as matrículas do alunado elegível ao atendimento pela educação especial na rede estadual por tipo de deficiência e verificar se esse incremento foi decorrente do acréscimo nas matrículas de estudantes em alguma(s) tipologia(s) com maior questionamentos quanto às formas e identificação, o que não foi realizado por não ser objetivo deste trabalho. 
Desse modo, observa-se que a trajetória crescente nos valores aluno/ano da educação especial no período de 2009 a 2019 refletiu no movimento de matrículas da educação especial. Nessa perspectiva, faz-se necessário analisar se a ampliação dos recursos voltados à educação especial no Fundeb e o aumento das matrículas reverberou nas despesas liquidadas dessa modalidade de ensino, nessa última década.

\section{Despesas com a função educação, subfunção educação especial e liquidadas com os recursos do Fundeb nas redes estaduais de São Paulo e Espírito Santo}

Nos relatórios do Siope - Demonstrativo da Função Educação e Relatório Resumido da Execução Orçamentária (RREO) -, do primeiro foram levantados os dados das despesas da função educação e da subfunção educação especial e, do segundo, os dados das despesas liquidadas com os recursos do Fundeb dos estados de São Paulo e Espírito Santo ${ }^{14}$. Nesse sentido, apresentam-se as Tabelas 2 e $3 \mathrm{com}$ a série histórica das despesas da função Educação, Liquidadas Fundeb e Subfunção Educação Especial, sendo que a Tabela 2 traz os dados de São Paulo e, a Tabela 3, os dados do Espírito Santo.

Tabela 2 - São Paulo: Despesas Função Educação, Liquidadas Fundeb e Subfunção Educação Especial (2009-2019) (R\$)

\begin{tabular}{|c|c|c|c|c|c|c|c|c|}
\hline Ano & $\begin{array}{c}\text { Despesas } \\
\text { Função Educạ }\end{array}$ & $(\%)$ & $\begin{array}{c}\text { Despesas } \\
\text { Liquidadas Fundeb }\end{array}$ & & $\begin{array}{c}\text { Percentual } \\
\text { das } \\
\text { Despesas } \\
\text { Liquidadas } \\
\text { Fundeb } \\
(\%)\end{array}$ & $\begin{array}{c}\text { Despesas } \\
\text { Sub-função Educação }\end{array}$ & Especial & $\begin{array}{c}\text { Percentual } \\
\text { das } \\
\text { Despesas } \\
\text { Sub-função } \\
\text { Educação } \\
\text { Especial } \\
(\%)\end{array}$ \\
\hline 2009 & $40.604 .371 .649,72$ & & $18.850 .077 .201,85$ & & 46,4 & $143.976 .344,94$ & & 0,4 \\
\hline 2010 & $45.522 .494 .892,97$ & 1 12,1 & 20.447.567.951,25 ن & 8,5 & 44,9 & $141.396 .658,89 \square$ & 1,8 & 0,3 \\
\hline 2011 & $47.764 .353 .749,99$ & 4,9 & $21.459 .865 .985,92$ 个 & 5,0 & 44,9 & $149.060 .841,24$ 它 & 5,4 & 0,3 \\
\hline 2012 & $40.634 .400 .397,86$ & 14,9 & $21.418 .637 .229,00 \downarrow$ & 0,2 & 52,7 & $147.857 .456,45 \mathbb{V}$ & 0,8 & 0,4 \\
\hline 2013 & $45.067 .203 .903,39$ & 10 10,9 & $22.256 .873 .030,89$ 仓 & 3,9 & 49,4 & $3.129 .800,49 \square$ & 97,9 & 0,01 \\
\hline 2014 & $51.421 .349 .770,02$ & ㄴ 14,1 & $20.669 .150 .382,82 \downarrow$ & 7,1 & 40,2 & $1.460 .900 .872,62$ 个 & $46.577,1$ & 2,8 \\
\hline 2015 & $49.872 .172 .946,39$ & 3,0 & $19.012 .838 .915,94 \square$ & 8,0 & 38,1 & $3.607 .093,25 \downarrow$ & 99,8 & 0,01 \\
\hline 2016 & $46.199 .184 .844,68$ & 7,4 & $17.552 .337 .349,37 \downarrow$ & 7,7 & 38,0 & $280.275 .868,94$ 个 & $7.670,1$ & 0,6 \\
\hline 2017 & $52.671 .393 .403,03$ & 仓 14,0 & $17.723 .748 .257,44$ 숨 & 1,0 & 33,6 & $58.013 .902,42 \downarrow$ & 79,3 & 0,1 \\
\hline 2018 & $38.382 .539 .519,72$ & 27,1 & $17.618 .442 .124,79 \downarrow$ & 0,6 & 45,9 & $85.972 .526,00$ 个 & 48,2 & 0,2 \\
\hline 2019 & $49.258 .305 .918,25$ & ثि 28,3 & $17.819 .755 .057,81$ 仓 & 1,1 & 36,2 & 215.227.277,50 仓 & 150,3 & 0,4 \\
\hline \multicolumn{2}{|c|}{2009 para 2019} & 仓 21,3 & 7 & 5,5 & & 仓े & 50,5 & \\
\hline
\end{tabular}

Nota: Valores corrigidos pelo IPCA (IBGE) dez/2019.

Fonte: Elaboração das autoras com base em FNDE/Siope - Demonstrativo da Função Educação (BRASIL, 2009 a 2019); Relatório Resumido da Execução Orçamentária (BRASIL, 2009 a 2019).

Na Tabela 2 pode-se observar que o estado de São Paulo apresentou ao longo do período de 2009 a 2019 despesas com a função educação que não se mantiveram em aumento constante, ocorreram quedas percentuais nessas despesas nos anos de 2012 (14,9\%), 2015 (3\%), 2016 (7,4\%) e 2018 (27,1\%), tendo como referência o ano anterior; ao

14 No portal do Siope temos entre os relatórios dos estados um Quadro Demonstrativo das Receitas e Despesas com o Fundo de Manutenção e Desenvolvimento da Educação Básica e de Valorização dos Profissionais, que apresenta as receitas e despesas dos recursos com esse fundo. Nele, as despesas com a subfunção educação especial não são demonstradas, assim, não foi possível identificar e analisar os valores liquidados com essa modalidade de ensino no âmbito do Fundeb. 
final do período o aumento nas despesas foi de $21,3 \%$, se cotejado 2019 em relação a 2009 . No ano de 2017 observa-se o maior valor aplicado - R\$ 52.671 bilhões e, em 2018, o menor - R\$ 38.382 bilhões. Logo, apesar de registrar-se no ano de 2019 o maior aumento percentual - 28,3\%, constata-se que esse teve relevância apenas para recuperar parte das perdas ocorridas nos anos anteriores.

Parte das despesas da função educação são liquidadas com os recursos do Fundeb, os valores liquidados com o fundo nesse período apresentaram variações percentuais. As quedas ocorreram em 2012 (0,2\%), 2014 (7,1\%), 2015 (8\%), 2016 (7,7\%) e 2018 (0,6\%) e observa-se que as três diminuições nos anos de 2014, 2015 e 2016 foram significativas para a redução dos valores ao final do período, que foi de 5,5\% (2009-2019). O maior valor liquidado com os recursos do Fundeb é constatado no ano de $2013-\mathrm{R} \$ 22.256$ bilhões e, o menor, em 2018 - R\$ 17.618 bilhões, correspondendo a 49,4\% e 45,9\% dos valores das despesas com a função educação para os respectivos anos. Percentualmente, os recursos do Fundeb para o estado de São Paulo representaram, excetuando-se o ano de 2012 (52,7\%), menos de $50 \%$ das despesas com a função educação, o que demonstra que o estado investiu, na maioria dos anos desse intervalo temporal, percentuais acima de $50 \%$ das despesas com essa função, além dos recursos advindos do Fundeb.

Araújo (2012), ao analisar os gastos efetivados em 2009 em creches, em alguns municípios brasileiros, observou que os recursos transferidos pelo Fundeb representavam $32,1 \%$ em Santa Catarina e 30,3\% do aplicado em São Paulo. Essa diferenciação de uso dos recursos nos municípios, demonstrados nos valores aplicados em 2009 e cobertos pelos valores repassados pelo Fundeb, pode ser compreendida pela capacidade de arrecadação de recursos próprios, que são determinantes para a ampliação do atendimento da educação básica.

Esse cenário, apontado por Araújo (2012), contribui para a compreensão do percentual abaixo de $50 \%$ de despesas financiadas, no estado de São Paulo, exclusivamente com os recursos do Fundeb. Assim, devido a sua capacidade de arrecadação tributária, apresenta elevado potencial de investimento na educação, a partir de recursos próprios.

As despesas com a subfunção educação especial apresentaram movimentos de quedas e aumentos que não foram coincidentes com os das despesas da função educação, conforme a Tabela 2, os valores se alteraram em alguns anos de forma expressiva para menos ou para mais. Na comparação com o ano anterior, as reduções das aplicações nessa despesa ocorreram nos anos de 2010 (1,8\%), 2012 (0,8\%), 2013 (97,9\%), 2015 (99,8\%) e 2017 (79,3\%); observa-se que três desses percentuais estão acima de $70 \%$, sendo que dois deles aproximam-se dos 100\%. Nos anos de 2014 e 2016 ocorreram aumentos atípicos com percentuais de $46.577,1 \%$ e $7.670,1 \%$, respectivamente; e, no ano de 2019 , um acréscimo de $150,3 \%$, que elevou a despesa a $\mathrm{R} \$ 215.227$ milhões. Esse aumento das despesas pode estar relacionado com a expansão de matrículas em 2014 e 2016 (Gráfico 2). No final do período, houve um incremento de $50,5 \%$ nessas despesas (2009 para 2019), o que poderia indicar, olhando somente para esse percentual, que o estado de São Paulo vem ampliando o financiamento da educação especial.

No tocante aos percentuais das despesas com a subfunção educação especial em relação às despesas com a função educação, observa-se que no período estes estiveram entre $0,01 \%$ e $2,8 \%$, sendo que, ao isolar o percentual mais alto e o mais baixo ocorridos entre 
2013 e 2015 , somente em 2016 o percentual ficou acima de $0,5 \%$ do total de despesas com a função educação do estado, foi de $0,6 \%$, variando nos outros anos entre $0,1 \%$ e $0,4 \%$. Ao relacionar esses resultados com os percentuais das matrículas da educação especial na rede estadual de São Paulo (Tabela 1), esses variaram entre 1,2\% em 2009 e 1,9\% em 2019, apresentando um aumento no período de $24,3 \%$, enquanto que o aumento das despesas com a subfunção foi de $50,5 \%$ (com grande variação no período). Desse modo, esses dois percentuais não trazem correspondência direta, pois os valores das despesas não são proporcionais ao quantitativo de matrículas, embora os valores percentuais de matrículas e despesas liquidadas tenham aumentado nesse período.

Nascimento (2012), ao analisar as despesas da subfunção educação especial no Brasil entre 2001 e 2010, considerando os dispêndios e o número de matrículas nessa modalidade, concluiu que os valores não chegavam a $1 \%$ das despesas totais da função educação. Bremaeker (2011), por sua vez, observou que nos municípios brasileiros as despesas com a subfunção em tela, no ano de 2008 , representou $0,42 \%$ das despesas com a função educação.

A Tabela 3 apresenta as despesas efetuadas com a função educação, as liquidadas com os recursos advindos do Fundeb e com a subfunção educação especial, conforme os relatórios do Siope do estado do Espírito Santo.

Tabela 3 - Espírito Santo - Despesas Função Educação, Liquidadas Fundeb e Subfunção Educação Especial (2009-2019)

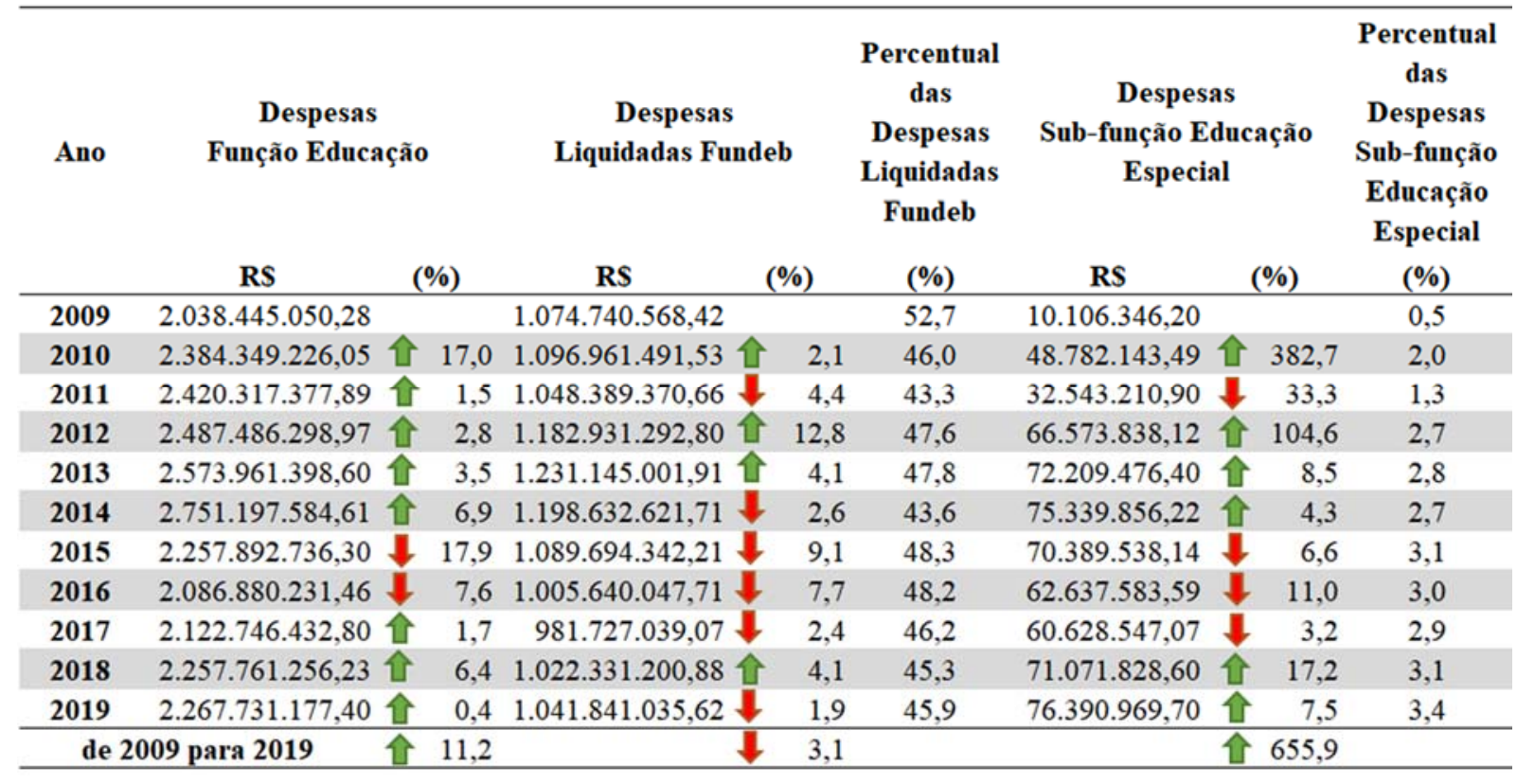

Nota: Valores corrigidos pelo IPCA (IBGE) dez/2019.

Fonte: Elaboração das autoras com base em FNDE/Siope - Demonstrativo da Função Educação (BRASIL, 2009 a 2019); Relatório Resumido da Execução Orçamentária (BRASIL, 2009 a 2019).

O estado do Espírito Santo por sua vez teve uma constância maior de aumento nas despesas da função educação entre 2009-2019. As quedas ocorreram apenas em dois anos seguidos em 2015 (17,9\%) e em 2016 (7,6\%); os aumentos variaram entre 0,4\% de 2018 para 2019 e $17 \%$ de 2009 para 2010 . O período encerra-se com aumento percentual de $11,2 \%$ nessas despesas. O maior valor aplicado nas despesas com a função educação foi em 2014 
- R\$ 2.751 bilhões, valor este que, após as quedas consecutivas nos dois anos seguintes, não foi recuperado chegando em 2019 , em R $\$ 2.267$ bilhões.

As despesas liquidadas com os recursos advindos do Fundeb tiveram ao longo do período mais quedas percentuais do que aumentos, somente em quatro anos foram registrados acréscimos, sendo que, ao final do período, a redução foi de $3,1 \%$. Os anos que registraram aumentos em relação ao anterior foram 2010 (2,1\%), 2012 (12,8\%), 2013 (4,1\%) e 2018 (4,1\%). Em 2017 ocorreu o menor valor de despesa - R\$ 981.727 milhões e o maior em 2013 - R\$ 1.231 bilhão. Com as diminuições de recursos entre 2014 e 2017, esse valor de 2013 não foi recuperado, e o período fechou em 2019 com R $\$ 1.041$ bilhão.

Percentualmente as despesas liquidadas com os recursos do Fundeb representaram, excetuando-se o ano de 2009 (57,7\%), menos de 50\% das despesas da função educação, sendo que nos dois últimos anos do período esteve na faixa dos $45 \%$. Assim como em São Paulo, o estado do Espírito Santo possui uma capacidade de arrecadação tributária e apresenta elevado potencial de investimento na educação, a partir de recursos próprios, para além dos recursos do Fundeb.

No Espírito Santo também não se observa o mesmo movimento das despesas com a subfunção educação especial em relação às despesas com a função educação. Ocorreram dois aumentos expressivos em 2010 e 2012 - 382,7\% e 104,6\%, respectivamente, em relação aos anos anteriores; ao passo que as quedas ocorreram nos anos de 2011 (33,3\%), 2015 (6,6\%), 2016 (11\%), 2017 (3,2\%). No final do período, o percentual de aumento foi de $655,9 \%$, que se pode considerar expressivo, pois as ocorrências de queda nos percentuais de despesas não influenciaram diminuição no percentual final. Os acréscimos nos dois anos finais, $17,2 \%$ (2018) e 7,5\% (2019), elevaram o valor da despesa para $\mathrm{R} \$ 76.390$ milhões, recuperando as perdas ocorridas entre 2015 e 2017.

Nos percentuais das despesas com a subfunção educação especial em relação ao total das despesas da função educação houve uma variação no período entre 0,5\% em 2009 e $3,4 \%$ em 2019, coincidentemente os anos de início e fim do período analisado. Pode-se afirmar que houve uma tendência de incremento do financiamento da educação especial no estado acompanhando o aumento dos percentuais das matrículas da educação especial na rede estadual - 2009 (0,5\%) e 2019 (3,4\%) (Tabela 1), um crescimento de 520,5\% no período; observe-se que o percentual de aumento nas despesas liquidadas com a subfunção no período foi maior que o das matrículas $(655,9 \%)$.

\section{Considerações Finais}

Este artigo teve a intenção de analisar os recursos da educação especial no contexto do Fundeb, a partir da análise dos dados de matrículas da educação especial, dos valores aluno/ano e despesas com a função educação, da subfunção educação especial, nos estados de São Paulo e Espírito Santo, no período de 2009 a 2019.

A educação especial, ao ser contemplada no Fundeb, como modalidade de ensino, com percentual diferenciado no fator de ponderação e ao contabilizar duplamente a matrícula do alunado elegível pelo atendimento da educação especial quando frequenta o $A E E$, representou um avanço para a materialização da política de educação especial na perspectiva inclusiva no Brasil. Isso, pois foram previstos, pela regulamentação desse fundo, recursos voltados a essa modalidade de ensino, que podem ser investidos na acessibilidade, recursos 
materiais e formação de profissionais, ou seja, nos apoios necessários para a ampliação do acesso e permanência desse alunado no contexto escolar.

As análises apontam que os recursos dirigidos à educação especial no Fundeb foram ampliados, na última década, por meio da trajetória ascendente dos valores aluno/ano. Em relação às despesas da educação especial, embora não seja possível analisar os valores específicos com essa modalidade de ensino no Fundeb, pelos demonstrativos do Siope, o movimento das despesas da subfunção específica também indica trajetória crescente em relação aos dispêndios destinados à educação especial. Contudo, o seu direcionamento pode ter contemplado outras etapas ou modalidades de ensino, nos respectivos estados, visto que o fundo não prevê a alocação de recursos exclusivos na educação especial.

Nessa direção, destaca-se o desafio à pesquisa em relação às fontes de dados, especificamente nos relatórios disponibilizados pelo Siope, haja vista que apenas o Demonstrativo de Despesas da Função Educação traz o registro das despesas da subfunção educação especial. No Quadro Demonstrativo das Receitas e Despesas com o Fundo de Manutenção e Desenvolvimento da Educação Básica e de Valorização dos Profissionais, as despesas com a educação especial não são registradas, pois não há um campo disponível nesse Quadro, o que impossibilitou a identificação dos valores liquidados com essa modalidade de ensino no âmbito do Fundeb.

Desse modo, o estudo aponta a necessidade de alteração nesses demonstrativos de despesas, a fim de garantir o acompanhamento e o controle dos recursos vinculados à educação especial.

Diante desse contexto, ratifica-se as proposições apresentadas no Manifesto Fundeb e Educação Especial (FINEESP, 2020), pela Rede de Pesquisadores sobre Financiamento da Educação Especial, em relação ao fortalecimento da transparência e do controle social da aplicação de recursos financeiros voltados a essa modalidade de ensino, bem como reiterase a importância da aprovação da proposta da Emenda à Constituição $n^{\circ} 15$, de 2015 , de relatoria da deputada federal Professora Dorinha S. Rezende (DEM/TO) (BRASIL, 2015), com as alterações propostas pela Campanha Nacional pelo Direito à Educação e Fineduca, para a reedição do Fundeb com a garantia de sua constitucionalização, de modo a torná-lo permanente e assegurar o direito à educação às pessoas com deficiência, TGD e altas habilidades/superdotação por meio da garantia de recursos financeiros.

\section{Referências}

ANUNCIAÇÃO, Marcos Paulo Pereira da; VERHINE, Robert Evan. A relação entre as variações no compromisso financeiro dos municípios com a educação e o desempenho escolar. Eccos: Revista científica, v. 8, n. 2, p. 253-504, jul./dez. 2006.

ARAÚJO, Raimundo Luiz Silva. Desvendando o perfil dos gastos educacionais dos municípios brasileiros. Educação \& Sociedade, Campinas, v. 33, n. 121, p. 1215-1233, out./dez. 2012.

BASSI, Marcos Edgar. Financiamento da educação e educação especial: política de fundos e inclusão em Santa Catarina. Poiésis - Revista de Pós-Graduação em Educação Mestrado do Sul de Santa Catarina, Tubarão, Unisul, v. 6, n. 10, p. 377-394, jul./dez. 2012. Disponível em: <https://bit.ly/2RZIXPi>. Acesso em: 22 out. 2018. 
BRASIL. Lei n. ${ }^{\circ} 4.320$, de 17 de março de 1964. Estatui normas gerais de direito financeiro para elaboração e controle dos orçamentos e balanços da União, dos Estados, dos Municípios e do Distrito Federal. Diário Oficial [da] República Federativa do Brasil, Brasília, 1964.

BRASIL. Congresso Nacional. Constituição da República do Brasil de 1988. Diário Oficial da União, Brasília, 1988. Disponível em: <https://bit.ly/2H0SpiU>. Acesso em: 18 nov. 2017.

BRASIL. Lei n. ${ }^{\circ}$ 9.394, de 20 de dezembro de 1996. Estabelece as diretrizes e bases da educação nacional. Diário Oficial da União, Brasília, 1996a. Disponível em: <https://bit.ly/2fWX88v>. Acesso em: 04 dez. 2017.

BRASIL. Lei n. ${ }^{\circ} 9.424$, de 24 de dezembro de 1996. Dispõe sobre o Fundo de Manutenção e Desenvolvimento do Ensino Fundamental e de Valorização do Magistério, na forma prevista no art. $60, \S 7^{\circ}$, do Ato das Disposições Constitucionais Transitórias, e dá outras providências. Diário Oficial da União, Brasília, 1996b. Disponível em: <https://bit.ly/2zfGS9l>. Acesso em: 11 dez. 2017.

BRASIL. Emenda Constitucional n. ${ }^{\circ} 53$, de 19 de dezembro de 2006. Dá nova redação aos arts. 7, 23, 30, 206, 208, 211 e 212 da Constituição Federal e ao art. 60 do Ato das Disposições Constitucionais Transitórias. Diário Oficial da União, Brasília, 2006. Disponível em: <https://bit.ly/2Xfhops>. Acesso em: 15 dez. 2019.

BRASIL. Decreto n. ${ }^{\circ}$ 6.253, de 13 de novembro de 2007. Dispõe sobre o Fundo de Manutenção e Desenvolvimento da Educação Básica e de Valorização dos Profissionais da Educação - FUNDEB, regulamenta a Lei $n^{\circ} .11 .494$, de 20 de junho de 2007, e dá outras providências. Diário Oficial da União, Brasília, 2007a. Disponível em: <https://bit.ly/2ZTnwVR>. Acesso em: 15 dez. 2019.

BRASIL. Casa Civil. Lei n. ${ }^{\circ} 11.494$, de 20 de junho de 2007. Regulamenta o Fundo de Manutenção e Desenvolvimento da Educação Básica e de Valorização dos Profissionais da Educação - FUNDEB. Diário Oficial da União, Brasília, 2007b. Disponível em: <https://bit.ly/1rXyQZ7>. Acesso em: 15 out. 2017.

BRASIL. Ministério da Educação. Secretaria de Educação Especial. Política Nacional da Educação Especial na Perspectiva da Educação Inclusiva. Brasília: MEC/Seesp, 2008. Disponível em: <https://bit.ly/20BktZT>. Acesso em: 20 jul. 2017.

BRASIL. Decreto n. ${ }^{\circ} .611$, de 17 de novembro de 2011. Dispõe sobre a educação especial, o atendimento educacional especializado e dá outras providências. Diário Oficial da União, Brasília, 2011a. Disponível em: <https://bit.ly/2TTks8B>. Acesso em 22 fev. 2018.

BRASIL. Campanha Nacional pelo Direito à Educação. Educação pública de qualidade: quanto custa esse direito? 2. ed. São Paulo: Campanha Nacional pelo Direito à Educação, $2011 b$.

BRASIL. Casa Civil. Lei n. ${ }^{\circ} 13.005$, de 25 de junho de 2014. Aprova o Plano Nacional de Educação - PNE e dá outras providências. Diário Oficial da União, Brasília, 2014. Disponível em: <https://bit.ly/1NE7LSh>. Acesso em: 20 jan. 2017.

BRASIL. Proposta de Emenda Constitucional n.15/2015. Brasília: Portal da Câmara, 2015. Disponível em: <https://bit.ly/3fczVcw>. Acesso em: 8 jun. 2020. 
BRASIL. Instituto Nacional de Estudos e Pesquisas Educacionais Anísio Teixeira. Sinopse Estatística da Educação Básica de 2010 a 2020. Brasília: Inep, 2019. Disponível em: <https://bit.ly/2Ke4QG8>. Acesso em: 10 maio 2020.

BRASIL. Fundo de Desenvolvimento da Educação. Sistemas de Informações sobre Serviços Públicos de Educação. Demonstrativos da Função Educação - Estado de São Paulo e do Espírito Santo - 2009 a 2019. Brasília, 2020a. Disponível em: <https://bit.ly/2Tx3OLM>. Acesso em: 22 abr. 2020.

BRASIL. Fundo de Desenvolvimento da Educação. Sistemas de Informações sobre Serviços Públicos de Educação. Relatório Resumido da Execução Orçamentária - RREO - Estado de São Paulo e do Espírito Santo - 2009 a 2019. Brasília, 2020b. Disponível em: <https://bit.ly/2Tx3OLM>. Acesso em: 22 abr. 2020.

BRASIL. Fundo Nacional de Desenvolvimento da Educação. Financiamento. Fundeb. Dados Estatísticos. Valor anual por aluno estimado, no âmbito do Distrito Federal e dos Estados, e estimativa de receita do Fundeb, 2009 a 2019. Brasília, 2020c. Disponível em: <https://bit.ly/2MgzyRn>. Acesso em: 22 abr. 2020.

BREMAEKER, François Eugene Jean de. A política de fundos para a educação e o impacto nas finanças dos estados e dos municípios. In: GOUVEIA, Andréa Barbosa; PINTO, José Marcelino Rezende Pinto; CORBUCCI, Paulo Roberto. Federalismo e políticas educacionais na efetivação do direito à educação. Brasília: Ipea, 2011. p. 51-68.

FINEESP. Rede de Pesquisadores sobre Financiamento Da Educação Especial. Manifesto Fundeb e Educação Especial. 2020. Disponível em: <http://www.redefineesp.fe.usp.br/>. Acesso em: 27 mai. 2020.

FRANÇA, Marileide Gonçalves. Financiamento da educação especial: complexas tramas, permanentes contradições e novos desafios. 2014. 364 f. Tese (Doutorado em Educação) Programa de Pós-Graduação em Educação, Faculdade de Educação, Universidade de São Paulo, São Paulo, 2014. Disponível em: <https://bit.ly/2S2cQky>. Acesso em: 15 out. 2017.

FRANÇA, Marileide Gonçalves; PRIETO, Rosângela Gavioli. Disputa pelo Fundo Público no financiamento da educação especial: correlações de forças entre o público e o privado. In: ENCONTRO ANUAL FINEDUCA, 6., 2018, São Paulo. Anais... São Paulo, 2018. p. 732-735. Disponível em: <https://bit.ly/3iPUHkz>. Acesso em: 15 jun. 2020.

GIL, Antônio Carlos. Como elaborar projetos de pesquisa. São Paulo: Atlas, 1991.

LOUREIRO, Aline Dozzi Tezza. A educação especial no município de Porto Ferreira-SP: 1972 a 2011. 2013. 140 f. Dissertação (Mestrado em Educação) - Programa de PósGraduação em Educação Especial, Centro de Educação e Ciências Humanas, Universidade Federal de São Carlos, São Carlos, 2013. Disponível em: <https://bit.ly/2Kcpelh>. Acesso em: 15 ago. 2018.

LÜDKE, Menga; ANDRÉ, Marli Elisa Dalmazo Afonso de. Pesquisa em Educação: Abordagens Qualitativas. São Paulo: EPU, 1986.

MARTINS, Paulo de Sena. O financiamento da educação básica por meio de fundos contábeis: estratégia política para a equidade, a autonomia e o regime de colaboração entre os entes federados. 2009. Tese (Doutorado em Educação) - Programa de Pós-Graduação, 
Faculdade de Educação, Universidade de Brasília, Brasília, 2009. Disponível em: $<$ https://bit.ly/2A8t2W7>. Acesso em: 30 jul. 2018.

NASCIMENTO, Ana Paula Santiago do. Avanços e retrocessos na oferta da educação infantil no Brasil: análise financeiro-orçamentária dos recursos destinados a essa etapa da educação 2001-2010. 2012. Dissertação (Mestrado em Educação) - Programa de PósGraduação em Educação, Universidade de São Paulo, São Paulo, 2012.

OLIVEIRA, Gildásio Macedo de. Financiamento das instituições especializadas na política de educação especial no estado do Espírito Santo (2012-2015). 2016. 144 f. Dissertação (Mestrado em Educação) - Universidade Federal do Espírito Santo, Vitória, 2016. Disponível em: <https://bit.ly/2FUQdsE>. Acesso em: 20 out. 2018.

OLIVEIRA, Gildásio Macedo de; SOBRINHO, Reginaldo Celio. Aspectos da sociodinâmica público e privado na política de educação especial no estado do Espírito Santo. Fineduca Revista de Financiamento da Educação, Porto Alegre, v. 10, p. 1-18, 2020. Disponível em: <https://bit.ly/31UIYfv>. Acesso em: 15 mar. 2020.

OLIVEIRA, Romualdo Portela de. O financiamento da educação. In: OLIVEIRA, Romualdo Portela de; ADRIÃO, Theresa (Org.). Gestão Financiamento e direito à Educação: análise da Constituição Federal e da LDB. 3. ed. São Paulo: Xamã, 2007. p. 83-122.

PEREIRA, Maria Aparecida Nunes. Financiamento da Educação Básica no Estado da Paraíba: análise dos primeiros resultados do Fundeb nos municípios de João Pessoa e Cabedelo - PB. 2012. 275 f. Tese (Doutorado em Educação) - Faculdade de Educação, Universidade Estadual de Campinas, Campinas, 2012. Disponível em: <https://bit.ly/2PDe9Wr>. Acesso em: 04 jul. 2018.

PINTO, José Marcelino de Rezende. 10 anos de Fundeb: o que aprendemos com a experiência. In: ENCONTRO ANUAL FINEDUCA, 5, 2017, Natal. Anais... Natal: Milarts Editora, 2017. Disponível em: <https://bit.ly/3dkqHtB>. Acesso em: 17 jan. 2018.

POLO, José Carlos. Planejamento e orçamento no município. In: BRASIL; FUNDESCOLA. Guia de consulta. Brasília: MEC, 1999. p. 295-329.

SÃO PAULO (ESTADO). Despesa orçamentária: conceitos, codificação e classificação. São Paulo, 2018. Disponível em: <http://twixar.me/WtN3>. Acesso em: 15 dez. 2018.

SOTO, Ana Paula de Oliveira Moraes et al. Financiamento da educação especial no Brasil na arena do público e do privado. Poiésis - Revista de Pós-Graduação em Educação, Mestrado do Sul de Santa Catarina, Tubarão, Unisul, v. 6, n. 10, p. 359-376, jul./dez. 2012. Disponível em: <https://bit.ly/2RZIXPi>. Acesso em: 22 out. 2018.

SOUZA, Marcia M.; CASTRO, Vanessa B. D.; PRIETO, Rosângela G. Plano Nacional de Educação 2014 e Plano Estadual de Educação 2016: implicações no financiamento da educação especial no Estado de São Paulo. Fineduca - Revista de Financiamento da Educação, v. 10, p. 1-16, 2020. Disponível em: <https://bit.ly/2O8bW29>. Acesso em: 15 jun. 2020.

SOUZA, Marcia Maurilio; PRIETO, Rosângela Gavioli. Política de financiamento da educação especial no estado de São Paulo e a relação público-privado: em foco o salário-educação. 
REPI-Revista Educação, Pesquisa e Inclusão, Boa Vista, v. 1, n. 1 (especial), p. 85-103, 2020. Disponível em: <https://bit.ly/2ZR3tpr>. Acesso em: 15 jun. 2020.

TEIXEIRA, Agda Lovato. O financiamento público da educação especial em Goiás - 2010 a 2013. 104 f. 2015. Dissertação (Mestrado em Educação) - Programa de Pós-Graduação em Educação, Universidade Federal de Goiás, Catalão, 2015. Disponível em: <https://bit.ly/2yDDW9V>. Acesso em: 15 jun. 2018.

Marcia Maurilio Souza é doutoranda em Educação - Educação e Ciências Sociais Desigualdades e Diferenças. Mestre em Educação pela Feusp, Graduada em Serviço Social pela Universidade São Francisco. É Bolsista da Coordenação de Aperfeiçoamento de Pessoal de Nível Superior (Capes). Integrante da Rede Fineesp.

ORCID: http://orcid.org/0000-0002-3975-7209

E-mail: marcia.maurilio@usp.br

Marileide Gonçalves França é graduada em pedagogia pela Universidade Federal do Espírito Santo (2005), Mestrado em Educação pela Universidade Federal do Espírito Santo (2008), Doutorado em Educação na Universidade de São Paulo (2014) e atualmente é professora da Universidade Federal do Espírito Santo. Tem experiência na área de Educação, atuando principalmente nos seguintes temas: política educacional; financiamento da educação, formação de professores; planejamento educacional, avaliação educacional, currículo escolar, educação especial e educação das relações étnico-raciais. Vicecoordenadora da Rede Fineesp.

ORCID: http://orcid.org/0000-0003-1690-6088

E-mail: leidemary8@gmail.com

Vanessa Dias Bueno de Castro possui licenciatura e bacharelado em Ciências Sociais e mestrado em Educação Escolar pela Faculdade de Ciências e Letras da Unesp campus Araraquara, doutorado em Educação pela Faculdade de Educação da USP. É professora da educação básica. Integrante da Rede Fineesp.

ORCID: http://orcid.org/0000-0003-1433-3669

E-mail:van.bcastro@gmail.com

Rosângela Gavioli Prieto é graduada em Pedagogia, pela Pontifícia Universidade Católica de Campinas e em Administração Escolar pela Universidade de Guarulhos; graduada em Psicologia pela Universidade de Guarulhos; mestre em Educação Especial (Educação do indivíduo especial) pela Universidade Federal de São Carlos; doutora em Educação pela Universidade de São Paulo. Atualmente, é professora da Faculdade de Educação da Universidade de São Paulo, onde foi chefe do Departamento de Administração Escolar e Economia da Educação (2009-2012); é coordenadora do Grupo de pesquisa CNPq Políticas de educação especial desde 2002. Coordenadora da Rede Fineesp.

ORCID: http://orcid.org/0000-0003-4013-1163

E-mail: rosangel@usp.br 


\section{Editores do volume 10}

Márcia Aparecida Jacomini - Universidade Federal de São Paulo, Brasil

José Marcelino de Rezende Pinto - Universidade de São Paulo, Brasil

\section{Comitê Editorial}

Nalú Farenzena - Universidade Federal do Rio Grande do Sul, Brasil

Juca Gil - Universidade Federal do Rio Grande do Sul, Brasil

Theresa Adrião - Universidade Estadual de Campinas, Brasil

Ângelo Ricardo de Souza - Universidade Federal do Paraná, Brasil

\section{Conselho Editorial}

\section{Alejandro Morduchowicz}

Universidad Pedagógica, Provincia de Buenos Aires, Argentina

Andréa Barbosa Gouveia

Universidade Federal do Paraná, Brasil

Fernanda Saforcada

Universidade de Buenos Aires, Argentina

Jacques Velloso

Universidade de Brasília, Brasil

João Monlevade

Senado Federal, Brasil

Jorge Abrahão de Castro

Instituto de Pesquisa Econômica Aplicada / IPEA, Brasil

Lisete Regina Gomes Arelaro

Universidade de São Paulo, Brasil

Luis Carlos Sales

Universidade Federal do Piauí, Brasil

Luiz de Sousa Junior

Universidade Federal da Paraíba, Brasil

Luiz Fernandes Dourado

Universidade Federal de Goiás, Brasil

Magna França

Universidade Federal do Rio Grande do Norte, Brasil

Marcos Edgar Bassi

Universidade Federal de Santa Catarina, Brasil

Maria Angélica Pedra Minhoto

Universidade Federal de São Paulo, Brasil

Maria Beatriz Luce

Universidade Federal do Rio Grande do Sul, Brasil

Maria Dilnéia Espíndola Fernandes

Universidade Federal de Mato Grosso do Sul, Brasil

Nelson Cardoso do Amaral

Universidade Federal de Goiás, Brasil

Nicholas Davies

Universidade Federal Fluminense, Brasil

Robert E. Verhine

Universidade Federal da Bahia, Brasil

Romualdo Portela de Oliveira

Universidade de São Paulo, Brasil

Rosana Gemaque Rolim

Universidade Federal do Pará, Brasil

Rubens Barbosa de Camargo

Universidade de São Paulo, Brasil

Theresa Adrião

Universidade Estadual de Campinas, Brasil

Tristan McCowan

University of London, Reino Unido

Vera Jacob

Universidade Federal do Pará, Brasil

Vera Peroni

Universidade Federal do Rio Grande do Sul, Brasil

Vitor Henrique Paro

Universidade de São Paulo, Brasil

\section{Equipe editorial}

Apoio ao Comitê Editorial: Caio Cabral da Silva

Diagramação, Revisão de português e normalização: Edson Leonel de Oliveira

Revisão de inglês: Sabrina Ferreira

Fineduca - Revista de Financiamento da Educação

Associação Nacional de Pesquisa em

Financiamento da Educação

e-mail: revista.fineduca@gmail.com | site: http://seer.ufrgs.br/fineduca 